November 2010

\title{
Modeling, Simulation and Analysis for Sustainable Product Development
}

\author{
Mahesh Mani $^{\mathrm{N}}$, Bjorn Johansson ${ }^{\mathrm{C}, \mathrm{N}}$ \\ Kevin Lyons $^{\mathrm{N}}$, Ram D. Sriram ${ }^{\mathrm{N}}$, Gaurav Ameta ${ }^{\mathrm{W}}$ \\ ${ }^{\mathrm{N}}$ National Institute of Standards and Technology \\ Manufacturing Systems Integration Division, Gaithersburg, MD \\ Email: \{mahesh,klyons,sriram\} @nist.gov \\ ${ }^{\mathrm{C}}$ Chalmers University of Technology \\ Product and Production Development \\ SE-412 96 Gothenburg, Sweden \\ Email: bjorn.johansson@chalmers.se \\ WWashington State University \\ Department of Mechanical Engineering, Pullman, WA \\ Email: gameta@wsu.edu
}

\begin{abstract}
Simulation plays a critical role in the design of products, materials and manufacturing processes. Increasingly, simulation is replacing physical tests to ensure product reliability and quality thereby facilitating steady reductions in design cycles. However, with the current global environmental crisis, there are gaps in the simulation tools used by industry to provide reliable results from which effective and equitable decisions can be made regarding environmental impacts at different stages of product realization and life cycle. For sustainable manufacturing planning, enhanced modeling techniques are needed to understand and predict the sustainability aspects through design and manufacturing where technologies can be applied to transform materials with reduced energy consumption, reduced emissions, reduced generation of waste products, and reduced use of non renewable or toxic materials. In this paper, a holistic and systems approach to Sustainable Manufacturing Planning and Simulation (SMPS) is identified and presented in an effort to bridge the gaps in the simulation tools to incorporate aspects pertaining to sustainability across the product lifecycle. For SMPS framework we consider building upon the previously developed Systems Integration of Manufacturing Applications (SIMA) project at NIST. Based on a case study and discussions we aim to address the usefulness of research towards having a simulation reference framework, and corresponding information models to facilitate effective decision making using simulation at different phases of product lifecycle. In the course of the paper we also identify and propose potential areas of future research in this direction.
\end{abstract}

Keywords: sustainable manufacturing, sustainable design, planning, simulations, systems approach, framework 


\section{Introduction}

Simulation is all-pervading in the industry and has proven to be a very effective approach for problem solving and optimization. It plays a critical role in the design of materials, manufacturing processes, and products. Increasingly, simulation is reducing the physical testing required to ensure process and product reliability and quality. For products, this results in fewer physical prototypes and shorter design cycles. Steady reductions in design cycles are crucial to remain competitive in a world where the pace at which new consumer products are being developed is ever increasing day to day, especially at a time of economic and environmental crisis. Despite these promising predictions for simulation, current research illustrates significant shortcomings and challenges in different areas. Overall, simulation in industry sees continuing growth while facing significant obstacles to meet its full potential. According to the Blue Ribbon Panel on Simulation-Based Engineering Science [1], simulation has yet to play a central role in important industrial and defense design applications. The reason is that large-scale simulation typically does not enter into the design cycle until its later phases. Model preparation, typically requires substantial amount of time and labor and to achieve the appropriate fidelity and accuracy months are taken to prepare a model. This may be followed by calibrated tests if the design is substantially different from previous designs.

Sustainable manufacturing [2, 3] has varying definitions depending on the context of discussion [See Appendix A]. It broadly implies the development of innovative manufacturing sciences and technologies that span the entire lifecycle of products and services to minimize negative environmental impacts, conserve energy and natural resources, are safe for employees, communities, and consumers, and are economically sound. In this paper we limit ourselves in exploring how modeling and simulation can augment sustainable manufacturing, by facilitating decision making across difference stages of product realization and lifecycle.

Law and McComas [4] reported that one of the primary application areas for modeling and simulation is in the area of manufacturing systems. In the literature, detailed discussions on modeling and simulation can be found in numerous books, among them Banks et al. [5] and Law and Kelton [6] are well known. The technology of utilizing discrete event simulation (DES), in particular, has been popular for numerous purposes other than manufacturing, such as patient flows in healthcare, military strategies, logistics, call centers and restaurants. Today sustainability considerations are increasingly relevant and require greater attention as industry needs to access the resource use increases. However, analysis and optimization of multiple objectives is not common in manufacturing simulation. DES in combination with Lifecycle Assessment (LCA) data is one possible approach for analyzing the cause and effect of various scenarios where time, resources, place, and randomness determine the outcome and being sustainable is considered crucial. For such analysis only a few research publications exist: Solding and Petku [7] and Solding and Thollander [8] both describe how DES can be utilized to lessen the electricity consumption for foundries. Ostergren et al. [9] and Johansson et al. [10] describe how DES can be 
utilized in combination with LCA for quantifying environmental impacts during food production. Based on the literature review, Table 1 summarizes the roles and the corresponding gaps in simulation for sustainable manufacturing. Table 2 correspondingly summarizes the manufacturing information and tool related problems with respect to simulation for sustainability.

Table 1 Simulation for sustainability: roles and gaps

\begin{tabular}{|l|c|}
\hline Roles & Gaps (resulting from a lack of) \\
\hline materials and manufacturing processes & $\begin{array}{l}\text { - metrics regarding sustainability } \\
\text { integration between design and simulation } \\
\text { tools }\end{array}$ \\
\hline - facilitates steady reductions in design cycles & $\begin{array}{l}\text { - support for sustainability in the simulation } \\
\text { tools } \\
-\quad \text { reliable results from which effective } \\
\text { and equitable decisions can be made } \\
\text { regarding environmental impacts }\end{array}$ \\
$\begin{array}{c}\text { enhanced modeling techniques } \\
\text { ability to understand and predict the } \\
\text { sustainability aspects through design } \\
\text { and manufacturing where technologies } \\
\text { can be applied to transform materials }\end{array}$ \\
\hline
\end{tabular}

Table 2 Sustainable manufacturing simulation: information and tool related problems

\section{Information related problems result from a lack of:}

- models that support simulation for sustainable product planning

- product-process-resource integration for simulation

- reference model for to identify and retrieve appropriate information

- interfaces between requirements-design, manufacturing and execution planning

- reasoning and decision support

\section{Simulation tool related problems result from a lack of:}

- integrated manufacturing planning and simulation

- characterization of manufacturing process resources

- integration of sustainability indications between tools

- extension beyond discrete event simulation

- sustainability metrics and indicators

With reference to DES, one of the key challenges is to define concepts and tools to incorporate attributes and metrics for various sustainability aspects in manufacturing enterprises. Case studies that incorporate sustainable manufacturing parameters for simulation need to be identified, including the evaluation metrics that incorporate the scoring of sustainability factors. Research efforts are also required to determine additional 
functional capabilities, validated sustainability reference data, and new information models to cater to the new challenges. But in order to realize SM, industries need an reference integrated framework, quantifiable measurement techniques and appropriate performance metrics to objectively evaluate all aspects of sustainable manufacturing (including energy efficiency, emissions, key process technologies, modeling and simulation, and standards) necessary to meet expected regulatory requirements. Research and development of new measurement methodologies and assessment technologies of product and process performance are also crucial to ensure sustainability in manufacturing.

The subsequent paper is organized as follows: in section 2 we present an initial simplified framework for sustainable manufacturing planning and simulation. Section 3 then discusses the scope of research primarily in two directions: a) integrated manufacturing planning and simulation and b) information models that support such integrated manufacturing planning and simulation for sustainability. In section 4, we discuss a case study to show how manufacturing simulation can help decision support across various tiers promoting sustainability. Finally in Section 5 we present our conclusions and the scope for future work.

\section{Sustainable Manufacturing Planning Methodology}

Our initial objective is to develop a holistic and systems approach to Sustainable Manufacturing Planning and Simulation (SMPS). Problem solving using a holistic, systems or concurrent engineering is not new and has been widely reported in the literature. What is new is the focus on sustainability. Figure 1 presents a simplified illustration of the proposed approach to SMPS. We draw inspirations from the earlier Systems Integration of Manufacturing Applications (SIMA) project at NIST. To set the stage, we represent the different phases of product realization namely design product, engineer manufacture of the product, engineer production system and produce products as planning tiers. Visualizing then as tiers further helps us understand how simulation results can be useful within and across these tiers. From Figure 1, the first tier represents the design of the product, the second is engineering the manufacturability of the product, and the third is the engineering the production system or manufacturing planning. The last phase is the actual production execution. Figure 2 presents a detailed view of the tiers with corresponding high level product realization activities. The figure additionally shows sustainability related information flow across the tiers. Figure 3 shows the corresponding SIMA manufacturing activity model reproduced from [11]. For details on the corresponding activity models within each tier, please refer [11].The following sub-sections briefly discuss the individual tiers. 


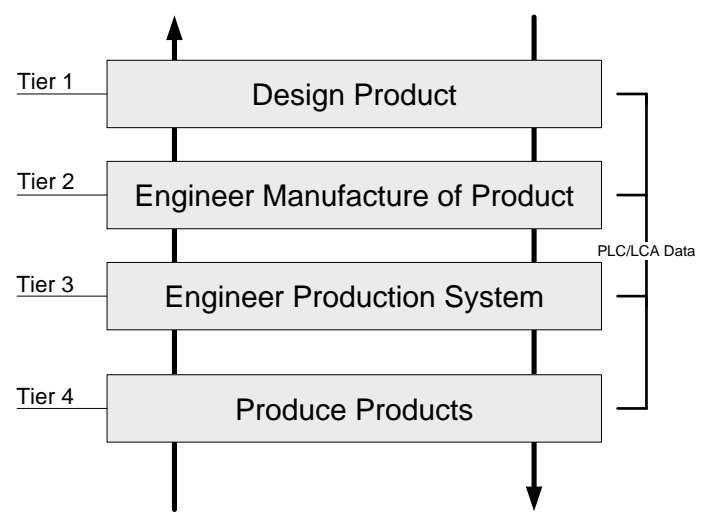

Figure 1. Typical stages in sustainable manufacturing planning and simulation

\subsection{Design Product}

When designing products, designers must cater for a multitude of technical, economic, social, environmental, and political requirements among others. This phase helps identify and conceptualize a marketable product, and create the complete description of it. With today's growing concerns for green products and green manufacturing, generating the right product and manufacturing specifications poses significant challenge. The activities in this phase as described in [11] include:

A11: Plan Products

A12: Generate Product Specifications

A13: Perform Preliminary Design

A131: Develop Functional Decompositions

A132: Evaluate and Select Decomposition

A133: Develop Preliminary Configurations

A134: Consolidate Configurations

A135: Evaluate Alternative Designs

A136: Select Design

A14: Produce Detailed Designs

A141: Design System/Component

A142: Analyze System/Component

A143: Evaluate System/Component Design

A144: Optimize Designs

A145: Produce Assembly Drawings

A146: Finalize System/Component Design

In order to respond to the increased demand for sustainability in product realization one can embrace total quality management (TQM) [13] as a means of understanding certain rules of thumb for good design analysis and planning in sustainable product and process development. For example, while generating product or system specifications one can introduce design requirements, constraints and the notion of value-added design constraints 
i.e., a constraint that favors improved resource utilization and reducing environmental impact. Value added constraints in general imply the addition of value to a product, process or service, with or without accompanying cost and price increases. Viewing them as value added design constraints provides the advantage of assigning weights for tradeoffs favoring specific constraints, sustainability constraints in this case.

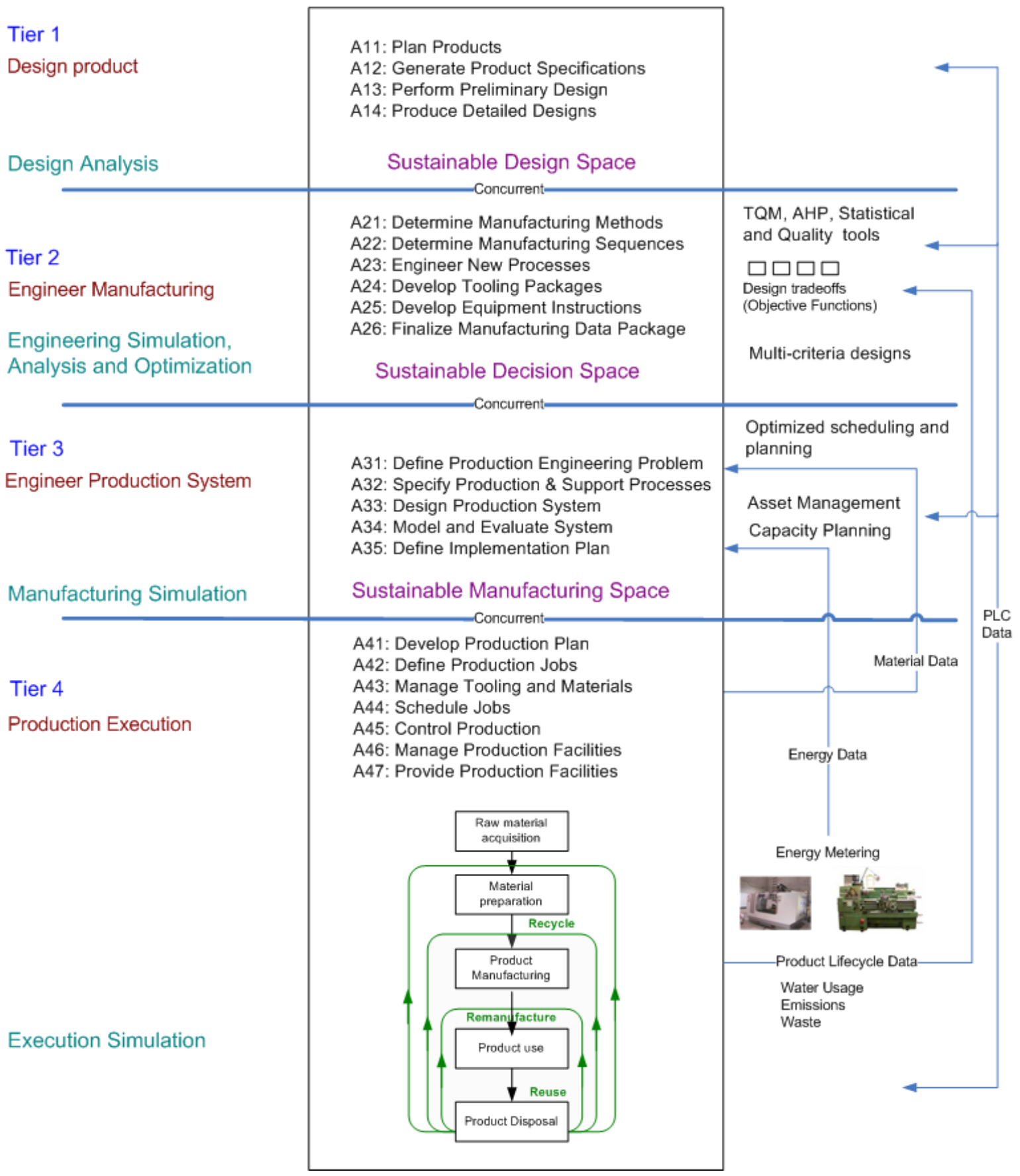

Figure 2 Integrated manufacturing planning and simulation 


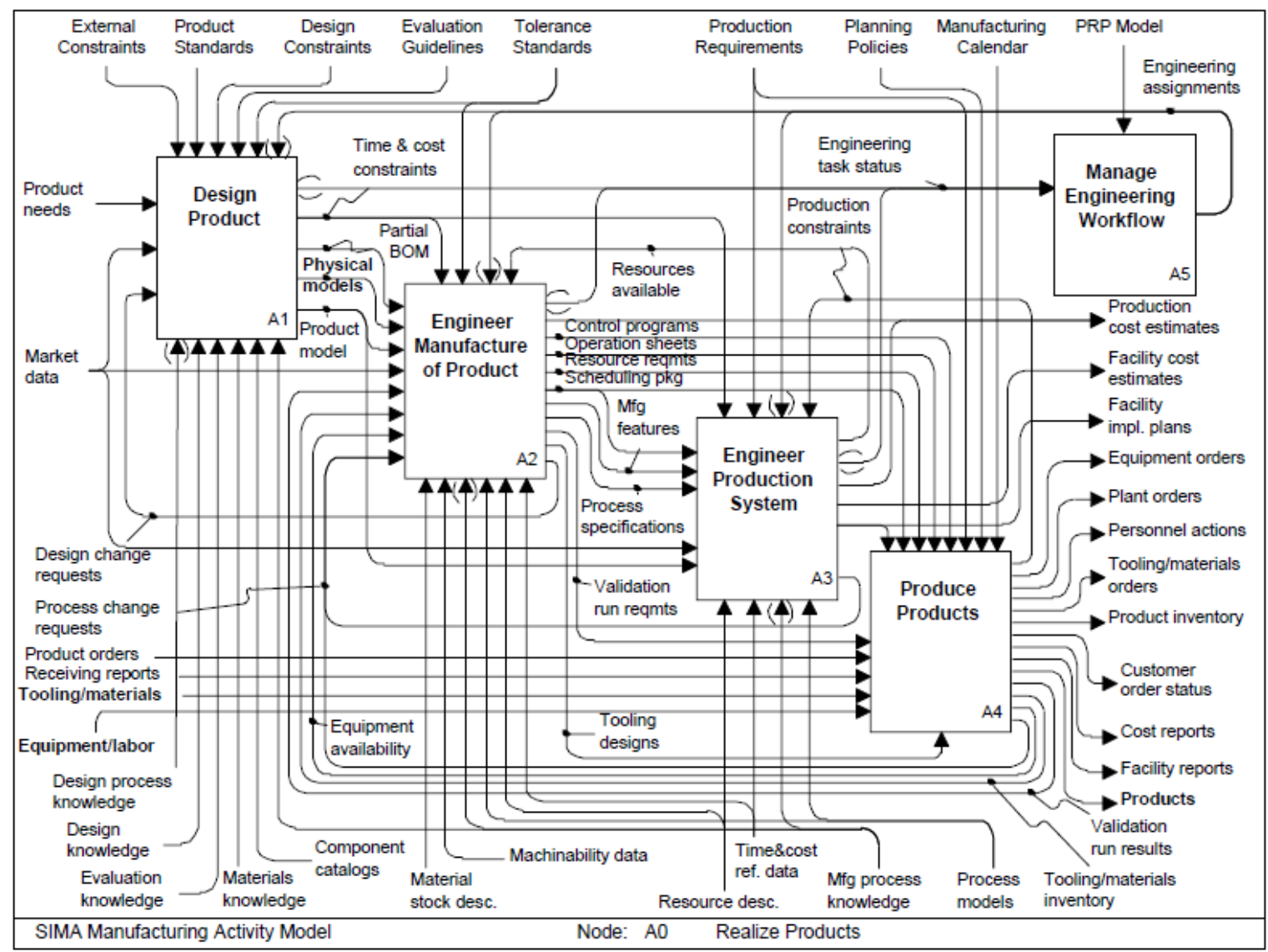

Figure 3 SIMA Manufacturing Activity Model: Realize products [11]

\subsection{Engineer Manufacture of Product}

This phase involves engineering the manufacturability of the product, i.e., defining the process of making the product, including the elementary stock materials and components to be acquired, the equipment, tooling and skills to be used and the details of that usage. Details include the exact sequence of setups and operations to be performed, and the complete instructions for each operation, whether by human or automated resources. By extension, the process of making the product includes measurement and inspection activities performed during production for process control and quality assurance. The activities in this phase as described in [11] include:

A21: Determine Manufacturing Methods

A211: Derive manufacturing features

A212: Select stock materials

A213: Select processes

A214: Select Major Resources

A215: Develop Preliminary Cost Estimates

A22: Determine Manufacturing Sequences

A221: Specify Operations 
A222: Sequence operations

A223: Specify Part Routing

A224: Optimize \& Validate Plan

A23: Engineer New Processes

A24: Develop Tooling Packages

A241: Select Tooling and Assemblies

A242: Design Tooling Assemblies

A243: Design Special Tooling

A244: Estimate Tooling Cost

A25: Develop Equipment Instructions

A251: Derive in-process work piece configurations

A252: Specify tooling requirements

A253: Generate Operator instructions

A254: Generate Machine Programs

A255: Validate equipment instructions

A26: Finalize Manufacturing Data Package

A261: Develop Final Cost Estimates

A262: Release Resource Package

A263: Release Scheduling Package

A264: Update Plan library

\subsection{Engineer Production System}

This phase involves the design of new or modified production facilities for the manufacture of a particular collection of Parts. A facility may be a plant, a shop, a line, a manufacturing cell, or a group of manufacturing cells. This activity encompasses both design-from-thewalls of such a facility and reengineering of all or part of such a facility to improve the production of certain products. It includes identification of the parts, products and processes for which the production system is to be tailored, identification of the equipment to be installed or replaced, (re)design of the floor layout, and development of an implementation plan for the (re)designed production system. The activities in this phase as described in [11] include:

A31: Define Production Engineering Problem

A311: Identify Project Type

A312: Identify Part Mix

A313: Identify Related Parts

A314: Identify Critical Dates

A315: Identify Target Costs

A316: Identify Manufacturing Constraints

A32: Specify Production \& Support Processes

A321: Specify Process Requirements

A322: Specify Process Flows

A323: Specify Materials Flow Requirements

A324: Specify Support Systems Requirements

A33: Design Production System 
A331: Specify Production Equipment

A332: Specify Control \& Automation Systems

A333: Develop Facility Layout

A334: Design Information System

A335: Integrate System Designs

A34: Model and Evaluate System

A35: Define Implementation Plan

\subsection{Production Execution}

This phase involves providing and maintaining the production facilities to produce the Parts according to the specifications in the process plans. This involves defining the production schedules and controlling the flow of materials into and out of the production facility, scheduling, controlling and executing the production processes themselves, providing and maintaining the production equipment and the human resources involved, developing and tracking the tooling and materials, etc. The activities in this phase as described in [11] include:

A41: Develop Production Plan

A411: Create Master Schedule

A412: Define Capacity Requirements

A413: Create Production Orders

A414: Monitor Production Orders

A42: Define Production Jobs

A421: Define Jobs

A422: Generate Tool and Stock orders

A423: Release Jobs

A424: Monitor Job Completion

A43: Manage Tooling and Materials

A44: Schedule Jobs

A441: Generate Job Schedule

A442: Generate Operations Schedules

A443: Generate Delivery Schedules

A444: Track Jobs

A45: Control Production

A451: Direct Personnel and Machines

A452: Control and Monitor Jobs

A453: Coordinate Equipment Groups

A454: Control Equipment

A46: Manage Production Facilities

A47: Provide Production Facilities

During product realization, besides considering planning for the disposal (Reuse, Remanufacture and Recycle) of the part, it is equally important to consider the implications of sustainable manufacturing. Modeling and simulation of manufacturing processes can provide excellent opportunities in this regard. A well defined reference architecture can 
support the ability to model and simulate product realization and end of life forecasts based upon historical trends of similar products, marketing programs and what-if scenarios. Such an architecture with reference to simulation can create opportunities for engineers to distribute cost, reliability, and environmental impacts of product manufacturing, component reuse, remanufacture, and recycling in such a way that the ends result is higher customer satisfaction than designing one product for all customer groups. More importantly, the analysis and simulation data accumulated across the various phases will support for equitable decision making.

\section{Envisioned reference architecture characteristics}

The following are the envisioned system level model characteristics based on the on the SMPS framework:

- Tiered approach: The four tiers, separated by naturally-defined boundaries, help to clarify specific engineering activities while also enabling local optimization.

- Concurrent planning: the frame work supports concurrent planning and looping wherein data exchange takes places between the different tiers

- Sustainability: Key Performance Indicators are quantifiable measurements that are incorporated into a model supporting their consideration throughout the PLC and collectively reflecting sustainability conformance.

- Systems approach: to optimization: the framework, by its structure, provides a systems approach to problem solving, taking a holistic approach where all tiers work in concert

- Boundaries: the framework, between tiers and within tiers, allows for boundaries to be set for measurement, analysis, and improvement

- Integrated life cycle assessment: LCA data can be dynamically linked for real time information management and assessment

- Model congruency: SMPS congruence is the state achieved by the tiers interacting for a state of agreement resulting in either sustainable products, processes or procedures.

- Standards Integration: supports linking of relevant standards to framework to check on regulatory compliance

\section{Research Directions}

We discuss the scope of research in two directions: 1) Integrated manufacturing planning and simulation and 2) information models that support such integrated manufacturing planning and simulation for sustainability.

\subsection{Integrated Manufacturing Planning and Simulation}

By developing a reference SMPS methodology and corresponding implementation one can expect the industry to simultaneously deal with trade-off factors such as manufacturability, cost, and environmental impact among others. With reference to Phase 3 in Figure 3, 
traditional production planning and control involves: forecasting, i.e. estimating the production demands using a horizon of a few months to a few years for long range planning, and production planning which is matching needed production to available resources. Today, with energy cost representing a considerable amount of the total production cost, energy savings has become a major concern for manufacturing companies [16-18]. For example, on a factory floor with large production lines many machines may be operating at the same time, and hence the peak energy consumptions will be generally high, incurring high cost. To minimize setup times and support automation, companies rely heavily on computer aided process planning (CAPP) [19-21] along with other manufacturing information systems to meet production queues. While cost, quality and lead time are the typical performance indices for manufacturability assessment in CAPP, introducing additional sustainability indices such as energy efficiency can result in desirable alternative plans [22].

Through integrated production planning and simulation one can expect to expedite both the top-down and bottom-up approaches to facilitate better decision-making. Figure 5 presents an exploded view of different manufacturing processes, sub-processes, and further going into the details at the individual equipments. The idea behind Figure 5 is to show how sustainable indicators and corresponding values can be aggregated from the machine level to a factory flow, or further aggregated to the plant level. In the engineering production system phase (Phase 3), one must be able to answer questions like which production plan best utilizes the facility's capabilities? which plan is most energy efficient? which is an optimal scheduling plan? or which are the energy efficient machines? Note that the proposed approach allows for answering questions at both a macro and micro level (e.g. manufacturing process level versus machine level). The immediate challenge, in terms of research, is how companies do this implementation and integration with other systems and what other technical and business areas can benefit from understanding energy usage. In manufacturing scheduling, it is often known well in advance what has to be produced. This can often lead to a near optimal schedule for all jobs, ahead of time. But these methods at the present time are not well enough developed to cater for the new trends in economic and environmental crisis.

Today, one of the important applications of simulation in manufacturing is discrete event analysis. Simulation is used to predict how complex systems will behave by incorporating functionality that incorporates random events, changing operating conditions and activities where many interactions are involved. Simulation typically involves developing a model that includes discrete stations and events that occur with some probability distribution. Simulation results are used to evaluate the modeled system based on machine utilization, lead time, down time, make-span, etc. Simulation is an effective tool when considering the effect of a change, comparing decision options, or refining a design. A well implemented framework would facilitate additional analysis and synthesis based on the overall improvement and asset management, in terms of environmentally friendly indices namely: manufacturing energy, cost vs. efficiency, time, material reduction, recyclability and reusability. As an example a discrete event simulation in Phase 3 could be useful to generate product specifications at Phase 1. The corresponding case study will be subsequently discussed in the paper. 
To support sustainable manufacturing from a regulatory and compliance point of view, standards and inspection procedures must be studied and incorporated in the new simulation models for raw materials, manufactured part, production process parameters, including verification and calibration. ISO has established related standards addressing Environmental Management and specifically life cycle assessment [24-26]. Figure 6 presents an initial mapping of relevant data required at various levels of simulation. For example in Phase 1, it involves the mapping of the engineering data, tools and appropriate standards for manufacturing planning.

Tier 3

Manufacturing Simulation

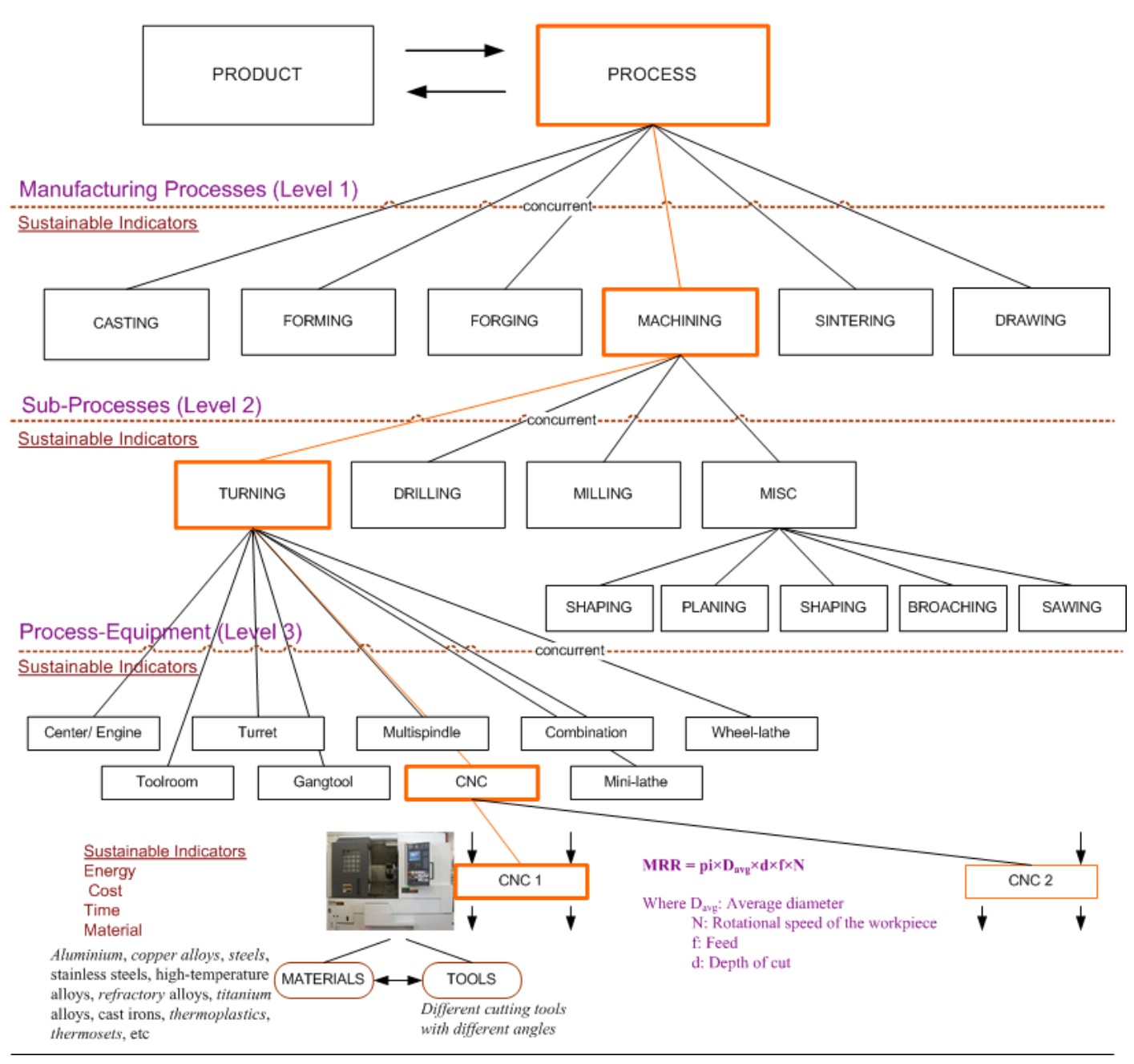

Figure 5 Manufacturing simulation (Phase 3) 


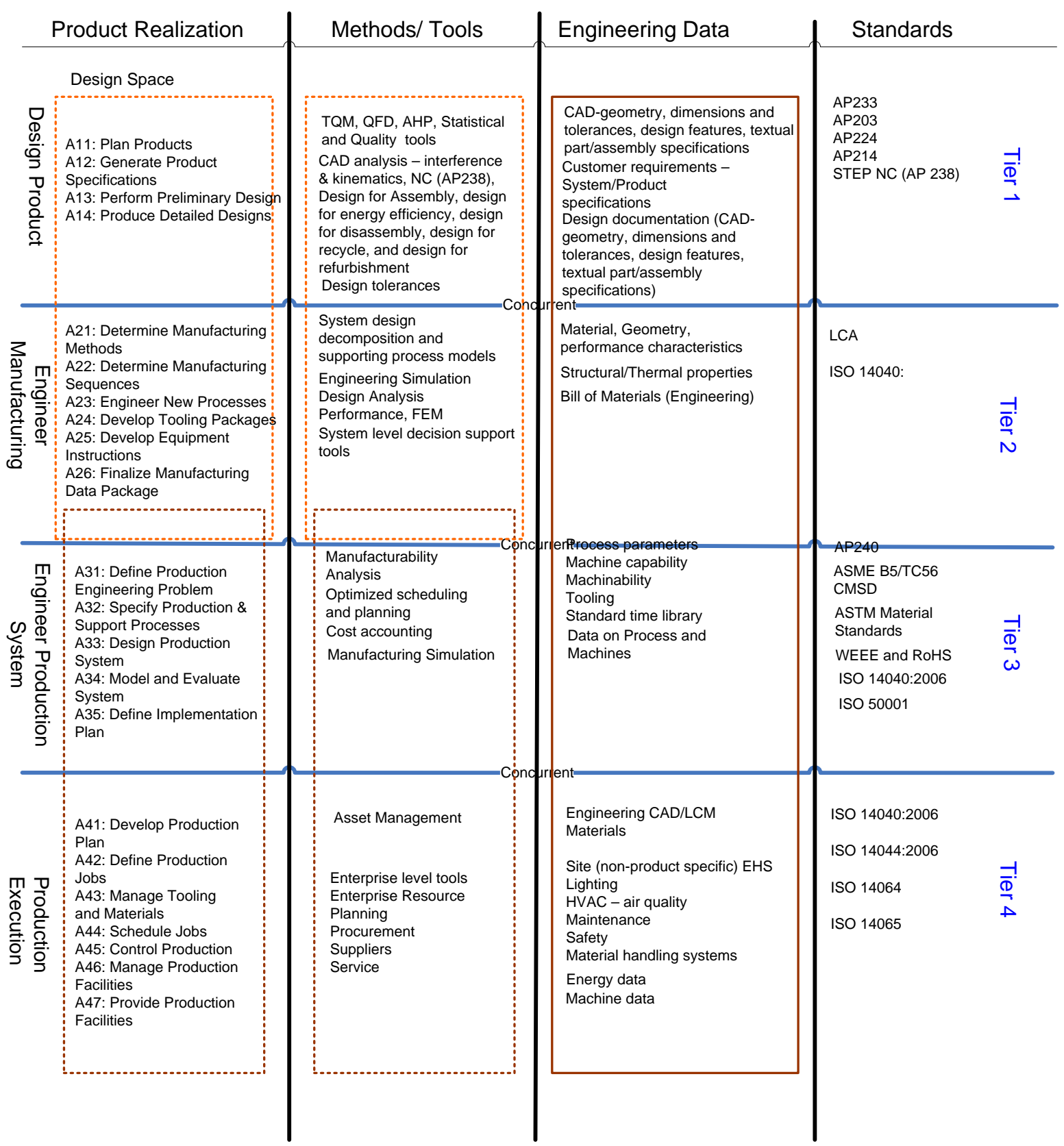

Figure 6 Initial mapping of relevant data required at various levels of product realization

\subsection{Models that support simulation for sustainable manufacturing}

Information management problems affect many aspects of manufacturing operations, but they are in particular a hindrance to the creation and reuse of manufacturing simulations. To be able to traverse across the different product creation phases information models that can support integrated planning and simulation (See Figure 6) are needed. The SMPS framework provides the opportunities to introduce sustainability factors to minimize 
environmental impacts at various stages of the product lifecycle. To support the SMPS framework we envision a corresponding well connected information model to support efficient management of data from characterization to simulation for sustainable manufacturing and planning. We call the information model as a Reference Information Model. Figure 7 illustrates the concept of a reference information model. The idea behind such an information model is to provide not only the adequate points of reference for information across the different phases but also to provide a mapping and interface between them.
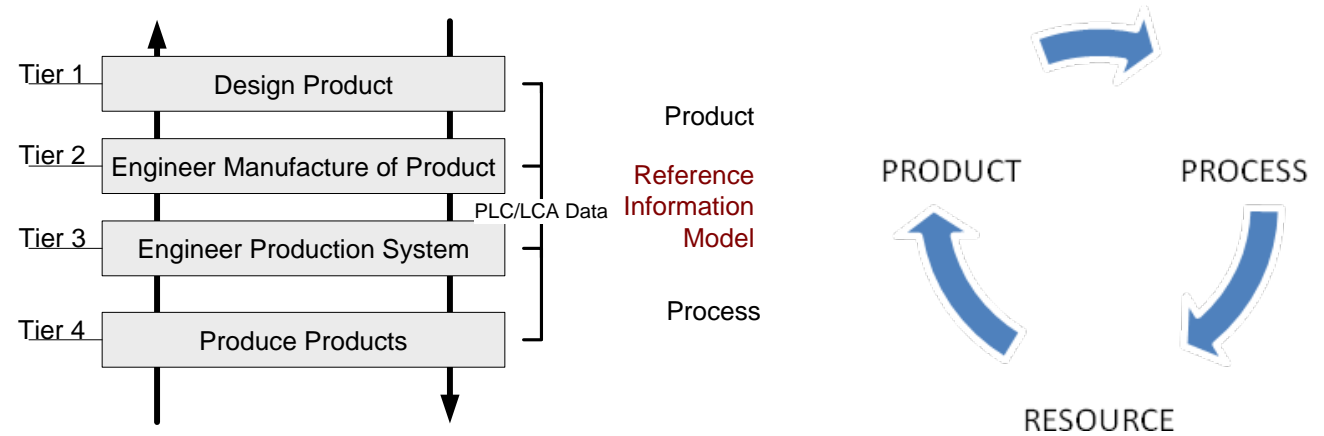

Figure 7 An information model that supports product-process-resource integration for Simulation

We envision that the new reference information model will facilitate the product-processresource integration and facilitate tradeoffs and multi-criteria decision support for sustainable manufacturing. Figure 8 presents a simple landscape of relevant data and standards for enabling information exchange. As shown in Figure 8, the idea is to explore how the reference information model will provide the appropriate interfaces and links between the various data models and standards across the different planning stages. Table 5 in the Appendix presents some relevant manufacturing data related standards.

The idea behind the connecting lines in figure 8 is to show that different information models can be used at different stages of product realization yet a coherent mapping or reference information is vital for successful information exchange across simulation applications. The Y. axis shows the product, process and resource information models mapped across the different product realization stages on the $\mathrm{X}$. axis. 


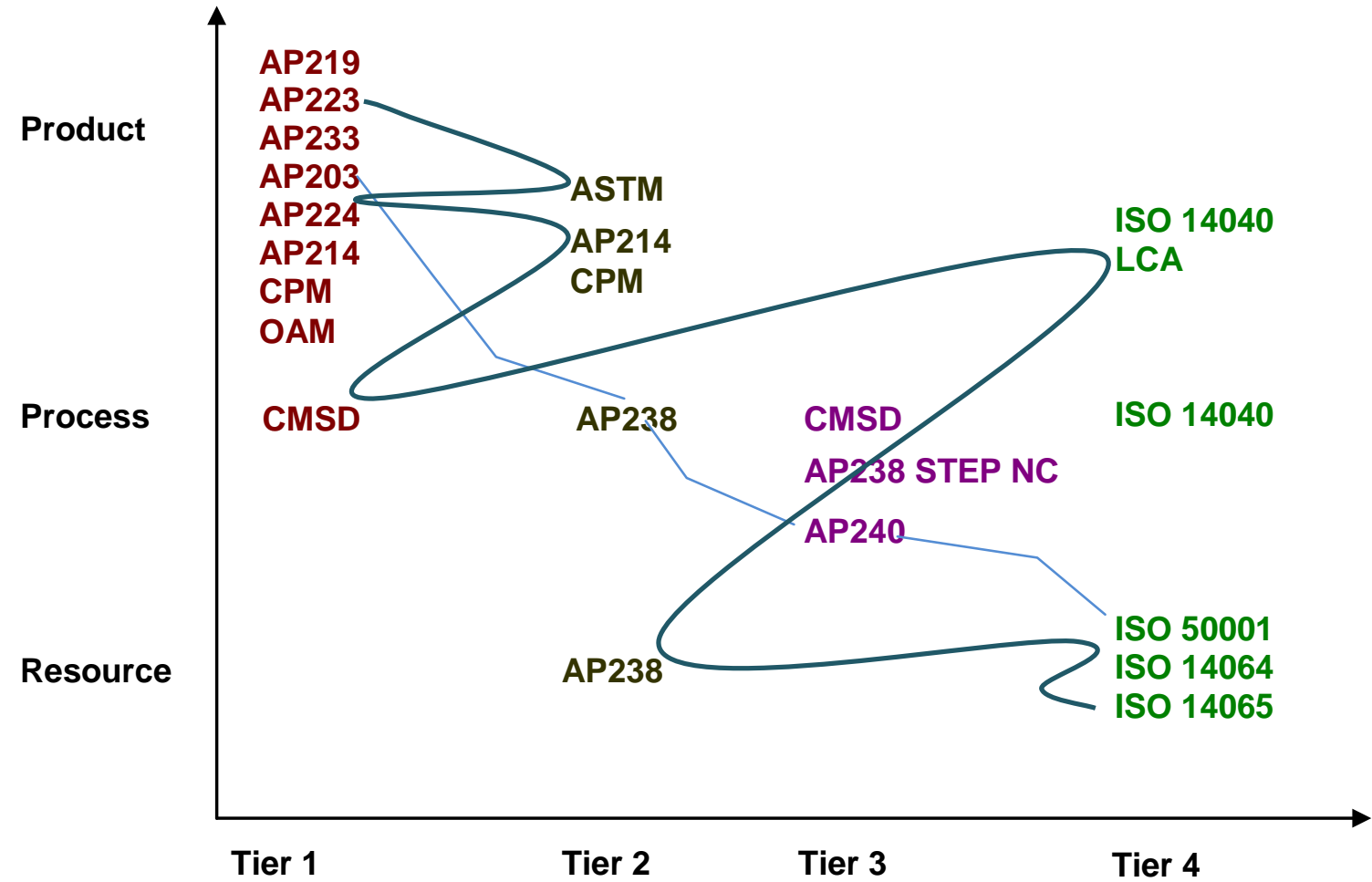

Figure 8 Landscape for enabling information exchange

There are number of useful implications one could envisage through sustainable manufacturing planning and simulation. Figure 9 presents the opportunities for manufacturing simulation, as means for analysis and optimization of machines and manufacturing processes to better implement sustainability strategies in an automotive manufacturing facility [27]. For example, energy efficiency trends of machines and manufacturing processes can be mapped and correlated.

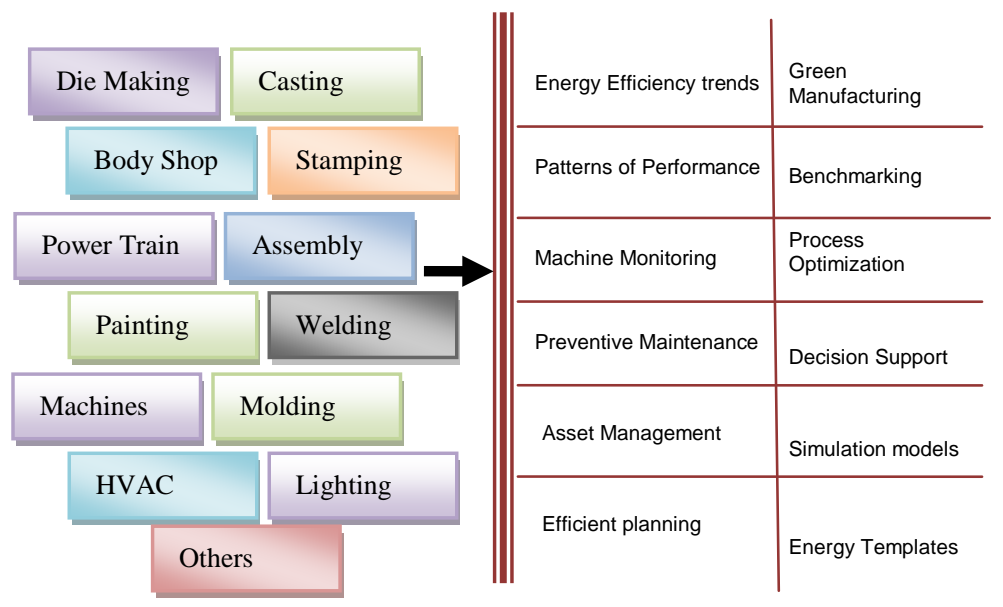

Figure 9 Implications of simulation models 


\section{Case Discussion}

\subsection{Industrial Scenario}

To set the stage, consider simulating the energy utilization of a typical automotive manufacturing facility. Figure 10 presents the energy composite in selected automotive manufacturing operations [28]. The boundaries are marked in red to signal the energy losses in the energy infrastructure of the auto industry. Marked in yellow are the energy intensive manufacturing processes.

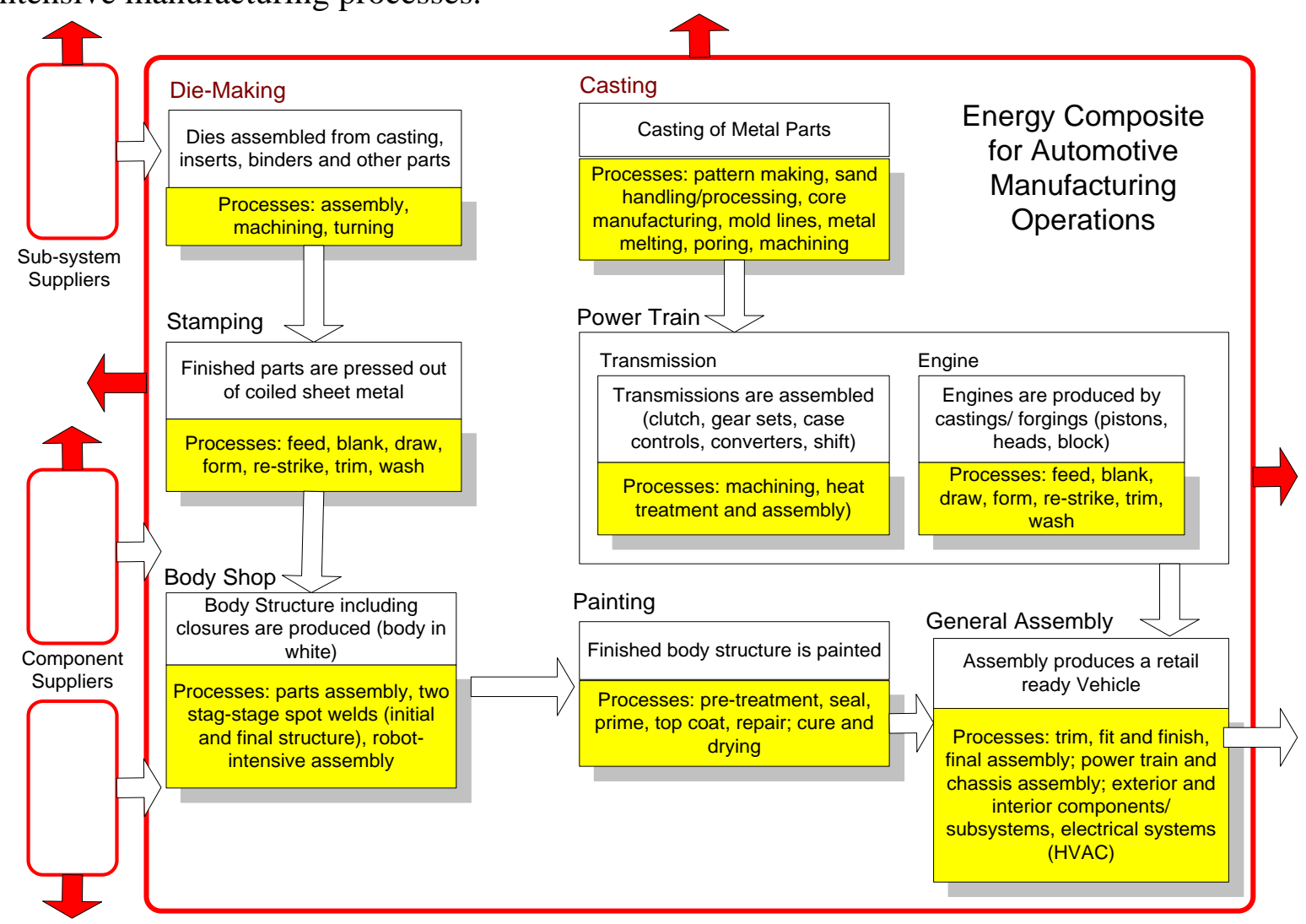

Figure 10 Energy composite for automotive manufacturing operations

Figure 11 below presents the corresponding breakdown of energy [42]. This is a rough estimate based on the on-site manufacturing processes while other subsystems and component suppliers are not accounted. Die-making and casting have been excluded because they are assumed to be captive operations (on-site) or out sourced and not included in the energy composite. There are multiple tests and inspection points that occur at various levels in between these operations. Further abatement occurs within all operations at some level. 


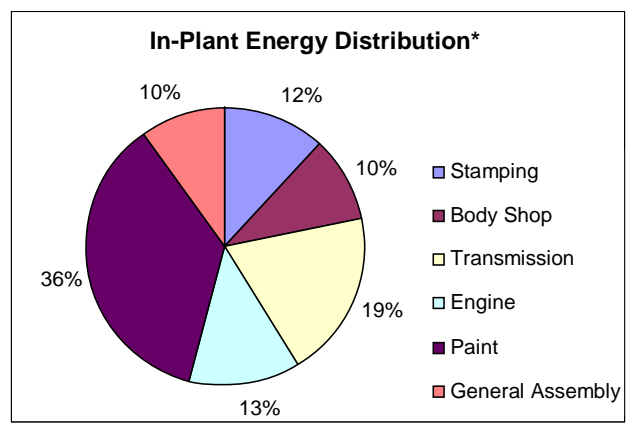

Figure 11 In-plant process energy distribution

From Figure 11, the paint shop consumes more energy than any other operation in the automotive industry. Within the paint shop, the conditioning of the air in the spray booths is the most energy-intensive process. Precise control of temperature and relative humidity in the paint booths are critical because it affects paint viscosity, or thickness which, in turn, affects the quality of the paint finish. Earlier, Bhattacharya from Honda [29], proposed a new control system that sets a tolerance window, provided by the paint supplier, rather than a fixed target. The new control system (knowledge based system), finds the temperature and relative humidity within that window that will require the least amount of heating, cooling or mist for humidity. It achieves energy savings by always directing the air to the least energy-intensive point within that tolerance window specified for production conditions. Figure 12 showing a snap shot of a paint shop simulation [30].
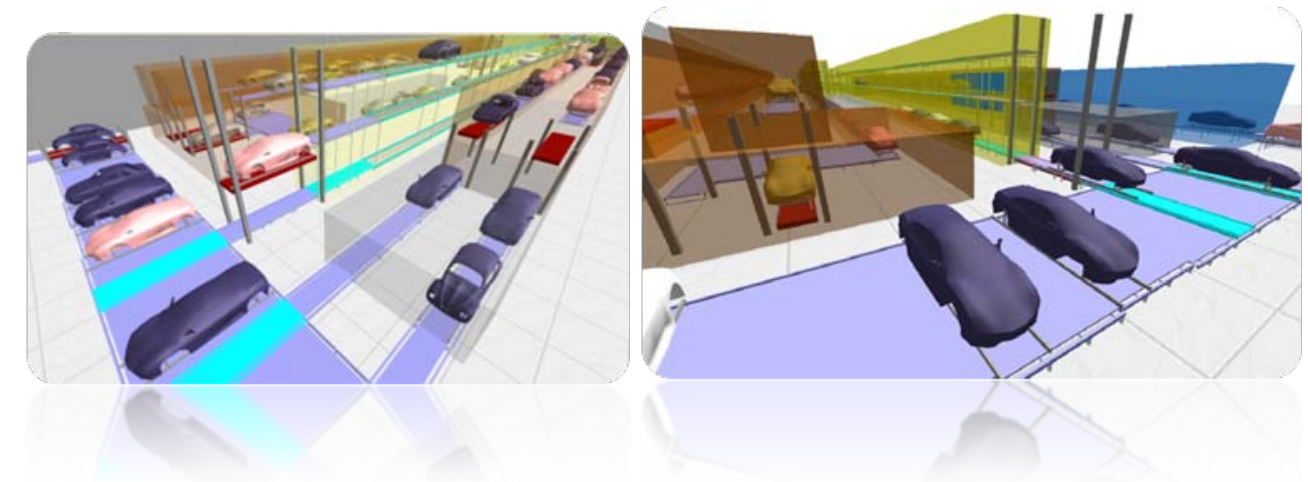

Figure 12 Paint shop simulation

The simulation tools used by industry must provide reliable results to cater for effective decisions towards sustainability and create opportunities to distribute the cost, reliability, and environmental impacts of energy use, emissions, waste, component reuse, remanufacture, and recycling in such a way that the end result is higher customer satisfaction. Since real-world phenomena are not deterministic, statistical methods that can quantify uncertainty will be needed. Considering design optimization, the constraints on the optimization of a product design relate to manufacturability, robustness, and a variety of other factors in addition to environmental sustainability. To be effective for engineering design, optimization methods must be closely coupled with simulation techniques. 


\subsection{Case Study}

To demonstrate a manufacturing planning scenario with an emphasis on sustainability, a simulation model has been built based on the work flow schematic as shown in Figure 13. The work flow schematic was adopted and modified from [31]. This scenario presents a paint shop with six painting steps to set the scene for requirements in an automotive paint shop. In terms of the simulation integration architecture the case study is also intends to demonstrate how simulation in one phase can help with decisions in another. Here we show how DES in phase 3 can be utilized to generate design requirements or specifications for manufacturing systems in the early design stage (Phase 1) or at the manufacturing planning stage [32]. Requirement specification denotes the description of the behavior of the system to be developed. The case study develops a prototype paint shop model which incorporates the use of LCA data in combination with DES and supports alternate decisions on energy use, choice of machines, and environmental bottleneck detection.

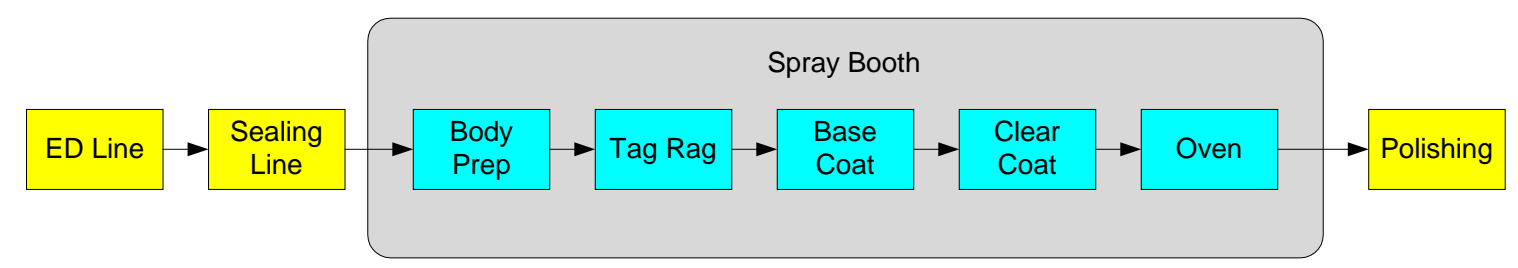

Figure 13 Example paint shop processes (adopted from Leng, and Yingchao 2005)

In Figure 3, the spray booth shows six steps (Body Preparation, Tag Rag, Base Coat, Clear Coat, Oven and Polishing) incorporated in the simulation model. The model was created based on some earlier work [33-35] as seen in Figure 14.

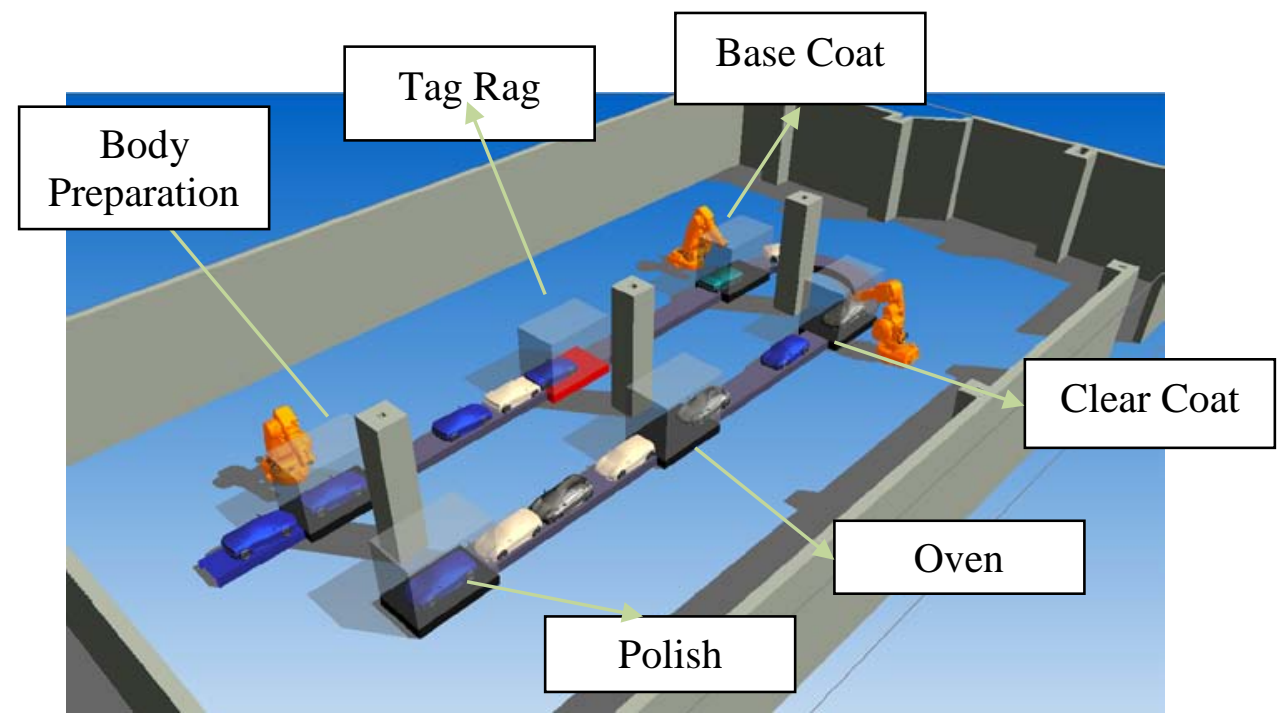

Figure 14 The 3D Simulation model of the paint shop 


\subsubsection{Input data to the Simulation model}

Each production step has a setting for the resource to be down, idle, or busy. Down means disconnected from the power provider, i.e., no electricity is used. Idle means that the resource is on standby, i.e., some electricity is used. Busy means doing the work cycle as such, i.e., electricity is used. Table 3 shows the input data specifying the energy use from the default settings in the paint shop model, as well as other data needed for setting parameters at the resources of the model such as cycle times, MTTF (Mean Time To Failure), MTTR (Mean Time To Repair), etc. The data herein presented are for the purposes of demonstration of our scenario and do not necessarily imply an actual paint shop data.

Table 3 Default settings for resources in the paint shop ${ }^{1}$

\begin{tabular}{l|c|c|c|c|c|c}
\hline Resource & $\begin{array}{c}\text { Body } \\
\text { Prep }\end{array}$ & $\begin{array}{c}\text { Tag } \\
\text { Rag }\end{array}$ & $\begin{array}{c}\text { Base } \\
\text { Coat }\end{array}$ & $\begin{array}{c}\text { Clear } \\
\text { Coat }\end{array}$ & Oven & Polish \\
\hline Processing Times & $\mathrm{n}$ & $\mathrm{n}$ & $\mathrm{n}$ & $\mathrm{n}$ & $\mathrm{n}$ & $\mathrm{n}$ \\
\hline Cycle time (Normal distribution) & 120 & 130 & 140 & 130 & 240 & 125 \\
\hline mean (Seconds) & 2 & 4 & 1 & 3 & 2 & 1 \\
\hline Standard deviation & 1 & 1 & 1 & 1 & 1 & 1 \\
\hline Energy (kW) & 5 & 4 & 50 & 50 & 1800 & 50 \\
\hline Down & 20 & 18 & 500 & 500 & 1800 & 200 \\
\hline Idle & $\mathrm{u}$ & $\mathrm{u}$ & $\mathrm{u}$ & $\mathrm{u}$ & $\mathrm{u}$ & $\mathrm{u}$ \\
\hline Busy & 1000 & 1200 & 1000 & 900 & 1000 & 900 \\
\hline Failures & 5000 & 5200 & 11000 & 10900 & 15000 & 4900 \\
\hline MTTF (Uniform distribution) & $\mathrm{n}$ & $\mathrm{n}$ & $\mathrm{n}$ & $\mathrm{n}$ & $\mathrm{n}$ & $\mathrm{n}$ \\
\hline Min (Seconds) & 240 & 260 & 600 & 590 & 1000 & 240 \\
\hline Max (Seconds) & 2 & 3 & 2 & 3 & 2 & 3 \\
\hline MTTR (Normal distribution)
\end{tabular}

\subsubsection{Case study Problem and Goal description}

When designing a new manufacturing system certain production goals and economic measures need to be fulfilled. For example, the production capacity is specified to be at least a certain level, the cost of the manufacturing system needs to be within the budget, and the environmental impact is expected to be below a certain guideline value. In this case study, the goals of the sustainable manufacturing system are assumed as follows:

- to reach a production capacity of at least 50000 cars per year,

- there will be no more than metric 500 tons of $\mathrm{CO}_{2}$ emission per year, and

- no new investment in equipment for the existing factory.

\footnotetext{
${ }^{1}$ The data herein presented are for the purposes of demonstration of our scenario and do not necessarily imply an actual paint shop data.
} 
The current factory is represented by the input data in Table 3, as well as the output data from Trial run 1 in Table 4.

\subsubsection{Simulation Experiments}

In this case study, the number of input variables are simplified to only a few choices as shown in Table 4. In a real world application however, a variety of designed operating parameters are considered based on the required system throughput. In the experiments, the number of input data parameters can be varied more extensively and practically anything feasible for a real world change could be varied if necessary to bring forth sound requirements specification for the considered manufacturing system.

From the initial settings (Trial run 1 in Table 4), the oven had been identified to be the bottleneck in terms of utilization as well as energy consumption. Some trial runs were performed based on different parameter settings. The settings included the energy source, oven cycle time, and energy consumption as well as a single or two ovens in parallel. The energy sources in the parameter setting included wind, water, or a mix of energy sources depending on the country where the factory is located.

The primary purpose of this simulation is to provide requirements specification support data, and hence also provide support towards designing a sustainable paint shop. In line with this effort, some examples of measures are provided in terms of energy, throughput and $\mathrm{CO}_{2}$ based on the simulation runs. In Table 4, from the twelve trial runs one can identify the bottlenecks, energy consumption and $\mathrm{CO}_{2}$ emissions due to energy type used in the paint shop. The results presented in Table 6 are calculated by running the simulation model. The model incorporates lifecycle assessment data from an European Union LCA database as described in [48].

Following are examples of conclusions arrived from looking at Table 4:

- The initial setting gives the lowest energy consumption per produced car, as well as trial 3 and 5

- The Oven is the throughput bottleneck initially (trial 1)

- Decreasing cycle time for the oven with 60 seconds does increase output of cars; however Oven is still the bottleneck.

- By adding another parallel oven, the Base Coat will be the bottleneck.

- Wind powered paint shop gives the lowest $\mathrm{CO}_{2}$ emissions (from energy) per car produced.

Note that the above conclusions are not the only items to consider, however they provide additional information and support a better decision space than a normal non-discrete event simulation analysis. Such information related to sustainability can be very useful for decision making across the different phases. 
Table 4 Simulation runs and their input data vs. output data changes

\begin{tabular}{|c|c|c|c|c|c|c|c|c|c|}
\hline \multirow[b]{3}{*}{ Trial run } & \multicolumn{3}{|c|}{ Input parameter changed } & \multicolumn{6}{|c|}{ Output data from the simulation run } \\
\hline & \multirow{2}{*}{$\begin{array}{l}\text { Oven cycle time and } \\
\text { energy use changed to } \\
180 \text { sec and } 2400 \mathrm{~kW}\end{array}$} & \multirow{2}{*}{$\begin{array}{c}\text { Energy source type } \\
\text { used in factory }\end{array}$} & \multirow[b]{2}{*}{$\begin{array}{c}\text { Number of } \\
\text { parallel Ovens }\end{array}$} & \multirow[b]{2}{*}{$\begin{array}{l}\text { Utilization } \\
\text { Bottleneck }\end{array}$} & \multicolumn{3}{|c|}{\begin{tabular}{|l|} 
Total per year \\
\end{tabular}} & \multicolumn{2}{|c|}{ Total per car } \\
\hline & & & & & Throughput & $\begin{array}{c}\text { Energy } \\
\mathrm{MWh}\end{array}$ & \begin{tabular}{|l|}
$\mathrm{CO}_{2}$ \\
Tons
\end{tabular} & $\begin{array}{c}\text { Energy } \\
\text { kWh }\end{array}$ & $\begin{array}{c}\mathrm{CO}_{2} \\
\mathrm{~kg}\end{array}$ \\
\hline 1 & 1 & 1 & 1 & Oven & 36556 & 3121,72 & 1744,6 & 85,4 & 47,72 \\
\hline 2 & 2 & 1 & 1 & Oven & 46620 & 4811,60 & 2689,0 & 103,2 & 57,68 \\
\hline 3 & 1 & 2 & 1 & Oven & 36556 & 3121,72 & 19,0 & 85,4 & 0,52 \\
\hline 4 & 2 & 2 & 1 & Oven & 46620 & 4811,60 & 29,3 & 103,2 & 0,63 \\
\hline 5 & 1 & 3 & 1 & Oven & 36556 & 3121,72 & 75,9 & 85,4 & 2,08 \\
\hline 6 & 2 & 3 & 1 & Oven & 46620 & 4811,60 & 116,9 & 103,2 & 2,51 \\
\hline 7 & 1 & 1 & 2 & Base Coat & 53280 & 5458,83 & 3050,7 & 102,5 & 57,26 \\
\hline 8 & 2 & 1 & 2 & Base Coat & 53280 & 5471,21 & 3057,7 & 102,7 & 57,39 \\
\hline 9 & 1 & 2 & 2 & Base Coat & 53280 & 5458,83 & 33,2 & 102,5 & 0,62 \\
\hline 10 & 2 & 2 & 2 & Base Coat & 53280 & 5471,21 & 33,3 & 102,7 & 0,63 \\
\hline 11 & 1 & 3 & 2 & Base Coat & 53280 & 5458,83 & 132,6 & 102,5 & 2,49 \\
\hline 12 & 2 & 3 & 2 & Base Coat & 53280 & 5471,21 & 132,9 & 102,7 & 2,50 \\
\hline
\end{tabular}

The left side of Table 4 shows the input data which is varied for the twelve runs. Column one on "Input parameter changed" can be set to either 1 for normal conditions or 2 for 180 sec cycle time and $2400 \mathrm{kWh}$. Column two shows which type of energy is used, 1 for an average country energy (i.e. mixed sources), 2 for wind power, 3 for water power. Column three shows the number of parallel ovens used in the model.

\subsubsection{Discussions}

The study results and output data are shown in Table 4. Constraints from the stated goals of the study have to be considered while analyzing the study results. To satisfy the goal to produce at least 50000 cars per year, Table 4 output data shows that trial runs 7-12 are feasible, however an investment in another oven will need to be added to the process. The next goal is to decrease the $\mathrm{CO}_{2}$ emissions to less than 500 metric tons per year. To reach this goal, standard fossil fuel energy cannot be used. Alternatively wind or water powered energy will need to be used. Table 4 shows trial runs 9-12 as feasible solutions with the use of "green" energy alternatives. In order to minimize the investment goal, the cycle time and energy consumption of the oven does not need to be changed. This means trial run 9 or 11 will be the preferred choice, depending on the energy cost from the power provider. It may be worthwhile to notice that the wind power could be a better choice than the water powered energy alternative in terms of $\mathrm{CO}_{2}$ emissions.

The study demonstrated that using the environmental measures from a LCA database and traditional input data with cycle time, disturbance data, etc. for discrete event simulation, new output measures from the model can be used to identify and analyze sustainable manufacturing system design and measures such as energy consumption at the aggregated shop floor level, resource level, and production throughput. Such analysis can also be useful in identifying the bottlenecks on any environmental measure; in this case the energy consumption and carbon footprint in relation to energy source used. 
Based on the described case study it would be desirable to be able to represent sustainability related data in a neutral format. One possible solution to store and use sustainability and other related data for discrete event simulation is to utilize the Core Manufacturing Simulation Data Information (CMSD) [36] specification, which allows us to maintain neutral and accessible measures.

\section{Conclusions and Future work}

In this paper, a holistic approach to Sustainable Manufacturing Planning and Simulation was identified necessary and presented in an effort to bridge the gaps in the simulation tools to incorporate aspects pertaining to sustainability. To augment the approach and methodology we present a case where simulation can be utilized to generate design requirements or specifications for manufacturing systems in the early requirements or design planning stage or at the manufacturing planning stage.

The proposed SMPS approach can help industry achieve benefits such as:

- minimize energy use and improve productivity through improved engineering of product and process through planning and simulation

- promote environmentally responsible and economically competitive businesses

- implement a comprehensive monitoring and preventive maintenance program that takes into consideration energy usage through simulation

- deploying energy indicators into any plans that include asset acquisition, allocation, or replacement

- awareness of environmental impact when taking decisions / holistic system viewpoint for increased cause vs. effect understanding

Potential future work will include all or any of the following directions: a good simulation reference architecture, investigate models that support various stages of planning, dynamic scheduling with integrated manufacturing resources, sustainable material flow analysis, characterization of manufacturing cells for sustainable engineering planning and simulation, mapping of relevant data required at various levels of simulation, develop a core manufacturing ontology for simulation purposes, integration and interoperability of information at various levels, case studies, science based engineering simulation for characterizing different manufacturing processes in terms of the energy (source, use and efficiency, key controlling parameters), identify the scope and boundaries, e.g., enterprise level, shop floor level, etc, integrated or extended simulation with design optimization processes to simultaneously deal with factors such as manufacturability, cost, and environmental impact, new models and representations that support simulation for sustainable manufacturing planning and the integration of simulation applications with other relevant engineering/ manufacturing applications.

\section{DISCLAIMER}

No approval or endorsement of any commercial product by the National Institute of Standards and Technology is intended or implied. 


\section{References}

[1] Report of the National Science Foundation Blue Ribbon Panel on Simulation-Based Engineering Science, Revolutionizing Engineering Science through Simulation, May 2006.

[2] http://www.ita.doc.gov/competitiveness/sustainablemanufacturing/how_doc_defines_SM.asp

[3] http://www.nacfam.org/PolicyInitiatives/SustainableManufacturing/tabid/64/Default.aspx/.

[4] Law, A.M., McComas, M.G. 1999. Simulation of Manufacturing Systems. In Proceedings of the 1999 Winter Simulation Conference, ed. P. A. Farrington, H. B. Nembhard, D. T. Sturrock, and G. W. Evans, Pheonix, AZ. pp. 56-59.

[5] Banks, J., Carson, J. S., Nelson, B. L., Nicol, D. M. 2000. Discrete-event system simulation. 3rd ed. Upper Saddle River, New Jersey: Prentice-Hall, Inc.

[6] Law, A. M., Kelton, W. D. 2000. Simulation modeling \& analysis. 3rd ed. New York: McGrawHill, Inc.

[7] Solding, P., Petku, D. 2005. Applying Energy Aspects on Simulation of Energy-Intensive Production Systems, in Proceedings of the 2005 Winter Simulation Conference, ed. Kuhl, M. E., Steiger, N.M., Armstrong, F. B., Joines, J. A., Orlando, FL, USA.

[8] Solding, P., and Thollander, P. 2006. Increased Energy Efficiency in a Swedish Iron Foundry Through Use of Discrete Event Simulation, in Proceedings of the 2006 Winter Simulation Conference, ed. Perrone, L. F., Wieland, F. P., Liu, J., Lawson, B. G., Nicol, D. M., Fujimoto, R. M. Monterey, CA, USA.

[9] Ostergren, K., Berlin, J., Johansson, B., Stahre, J., Tillman, A-M., 2007. A tool for productive and environmentally efficient food production management. European conference of Chemical Engineering, Copenhagen 16-20 September 2007.

[10] Johansson, B., Stahre, J., Berlin, J., Östergren, K., Sundstrom, B., Tillman, A.M., 2008, Discrete Event Simulation with Lifecycle Assessment data at a Juice Manufacturing System, in proceedings of the 5th FOODSIM.

[11] Barkmeyer J. E., (Ed)SIMA Reference Architecture. Part 1: Activity Models, NISTIR 5939.

[12] Masanet, E., Horvath, A., California Air Resources Board's Chair's Air Pollution Seminar, http://industrial-energy.lbl.gov/node/402/.

[13] Oakland J. S. Total Quality Management, Butterworth-Heinemann Publishers, 2003

[14] Saaty T.L. Decision making with the analytic hierarchy process, International Journal of Services Sciences, Volume 1, Number 1, pp 83 - 98.

[15] Akao, Y. 2004. Quality function deployment: integrating customer requirements into product design, Productivity Press.

[16] Energy Efficiency, Water and Waste-Reduction Guidebook for Manufacturers: Proven Ways to Reduce Your Costs and Improve Operations, http://www.energysavings.gov/.

[17] Energy Efficiency, Water and Waste-Reduction Guidebook for Manufacturers: Proven Ways to Reduce Your Costs and Improve Operations, http://www.nam.org/s_nam/bin.asp?TrackID=\&SID=1\&DID=233434\&CID=89\&VID=2/.

[18] Partners in Practice, Guidelines for Energy Management, http://www.energystar.gov/index.cfm?fuseaction=partners_in_practice.showHome/.

[19] Dong, J.J., Parsaei, H.R., Leep, H.R., Manufacturing process planning in a concurrent design and manufacturing environment, Computers \& Industrial Engineering Volume 30 (1996), pp 83-93.

[20] Li, L., Fuh, J. Y.H., Zhang, Y. F. and Nee, A. Y.C. (2005) Application of genetic algorithm to computer-aided process planning in distributed manufacturing environments. Robot. Comput.Integ. Mfg, 21, pp. 568-578. 
[21] Mahesh, M., Ong, S.K., Nee, A.Y.C., Fuh, J.Y.H., Zhang, Y.F., Towards A Generic Distributed and Collaborative Digital Manufacturing, Robotics and Computer Integrated Manufacturing, Vol. 23, No 3 (2007), pp 267-275.

[22] Mahesh M, Lyons, K., Sudarsan R, Feng S.C, Sriram R.D, Ameta, G., "Introducing Sustainability indices early into Manufacturing Process Planning and Scheduling”, Proceedings of the 14th International Conference on Manufacturing Science and Engineering, ASME, October 07-10, 2008.

[23] Ameta G, Mahesh M, Sudarsan R, Feng S.C, Sriram R.D, Lyons K., 'Carbon weight analysis for machining operation and allocation for redesign' , International Journal of Sustainable Engineering, Volume, Issue 4 December 2009 , pages 241 - 251.

[24] ISO. 1997. Environmental Management - Life Cycle Assessment - Principles and Framework. ISO 14040:1997. European Committee for Standardization CEN, Brussels, Belgium.

[25] ISO. 1998. Environmental Management - Life Cycle Assessment - Goal and Scope Definition and Inventory Analysis. ISO 14041:1998. European Committee for Standardization CEN, Brussels, Belgium.

[26] ISO. 2000. Environmental Management - Life Cycle assessment - Life Cycle Interpretation. ISO 14043:2000. European Committee for Standardization CEN, Brussels, Belgium.

[27] Mahesh M, Lyons K, Ameta G, "Introducing Sustainability indices early into Manufacturing Process Planning and Scheduling”, Proceedings of the 14th International Conference on Manufacturing Science and Engineering, ASME, October 07-10, 2008.

[28] Technology Roadmap for Energy Reduction in Automotive Manufacturing, Workshop Report, U.S. Council for Automotive Research, 2008.

[29] http://www.autonews.com/article/20080811/ANA03/808110336/.

[30] Johansson, B., Fasth, Å. Stahre, J., Heilala, J., Leong, S., Lee, Y. T., Riddick, F. 2009. Enabling Flexible Manufacturing Systems by Using Level of Automation as Design Parameter. In Proceedings of the 2009 Winter Simulation Conference, eds. M. D. Rossetti, R. R. Hill, B. Johansson, A. Dunkin and R. G. Ingalls, Piscataway, New Jersey: Institute of Electrical and Electronics Engineers, Inc.

[31] Leng, and Yingchao 2005

[32] Johansson, B., Mahesh, M., Skoogh, A., Leong, S. Discrete Event Simulation as Requirements Specification for Sustainable Design of Manufacturing Systems. Proceedings of the PERMIS Workshop. NIST 2009.

[33] Heilala, J., Saija, V., Tonteri, H., Montonen, J., Johansson, B., Stahre, J., Lind, S. 2008. SimulationBased Sustainable Manufacturing System Design, In Proceedings of the 2008 Winter Simulation Conference, eds. Mason, S. J., Hill, R. R., Mönch, L., Rose, O., Jefferson, T., Fowler, J. W. 19221930, Piscataway, New Jersey: Institute of Electrical and Electronics Engineers, Inc.

[34] Lind, S., Krassi, B., Viitaniemi, J., Kiviranta, S., Heilala, J., Berlin, C. 2008. Linking Ergonomics Simulation to Production Process Development, In Proceedings of the 2008 Winter Simulation Conference, eds. S. J. Mason, R. R. Hill, L. Mönch, O. Rose, T. Jefferson, and J. W. Fowler, 19681973, Piscataway, New Jersey: Institute of Electrical and Electronics Engineers, Inc.

[35] Lind, S., Krassi, B., Johansson, J., Viitaniemi, J., Heilala, J., Stahre, S., Vatanen, S., Fasth, Å., Berlin C., 2008. SIMTER: A Production Simulation Tool for Joint Assessment of Ergonomics, Level of Automation and Environmental Impacts. The 18th International Conference on Flexible Automation and Intelligent Manufacturing (FAIM 2008), June 30 - July 2, 2008.

[36] SISO 2009. Standard for Core Manufacturing Simulation Data Information Model: UML model (Draft) CMSD Product Development Group, Simulation Interoperability Standards Organization. http://www.sisostds.org/index.php?tg=fileman\&idx=get\&id=49\&gr=Y\&path=Papers+and+Present ations\&file=06F-SIW-028_final.pdf/.

[37] http://www.steptools.com/support/stdev_docs/express/ap203/.

[38] http://www.autofieldguide.com/articles/109902.html/.

[39] http://www.steptools.com/support/stdev_docs/express/ap219/. 
[40] http://www.sfsa.org/sfsa/news/2005/april05.pdf/.

[41] http://www.steptools.com/support/stdev_docs/express/ap224/.

[42] http://www.ap233.org/.

[43] http://www.steptools.com/support/stdev_docs/express/ap238/.

[44] http://www.steptools.com/support/stdev_docs/express/ap240/.

[45] http://www.igi-global.com/reference/details.asp?ID=9684\&v=preface/.

[46] http://www.sisostds.org/index.php?tg=fileman\&idx=get\&id=49\&gr=Y\&path=Papers+and+Present ations\&file=06F-SIW-028_final.pdf/.

[47] http://www.iso.org/iso/catalogue_detail?csnumber=37456/.

[48] http://www.iso.org/iso/catalogue_detail?csnumber=38381/.

[49] http://www.iso.org/iso/catalogue_detail?csnumber=40685/.

[50] http://www.iso.org/iso/pressrelease?refid=Ref1157/.

[51] http://www.steptools.com/library/standard/step_4.html/.

[52] http://ts.nist.gov/standards/iges/.

\section{Appendix A:}

Department of Commerce (DOC)

For the purposes of Commerce's Sustainable Manufacturing Initiative, sustainable manufacturing is defined as the creation of manufactured products that use processes that minimize negative environmental impacts, conserve energy and natural resources, are safe for employees, communities, and consumers and are economically sound [2].

\section{National Council for Advanced Manufacturing (NACFAM)}

Sustainable manufacturing includes the manufacturing of "sustainable" products and the sustainable manufacturing of all products. The former includes manufacturing of renewable energy, energy efficiency, green building, and other "green" \& social equity-related products. NACFAM aims to address both of these topic areas and emphasize the sustainable manufacturing of all products taking into account the full sustainability life cycle issues related to the products manufactured [3].

NACFAM uses the definitions above and build off the concepts of the triple bottom line (developed by John Elkington [52]) and sustainable enterprise. The triple bottom line emphasizes financial profitability, environmental integrity, and social equity. This concept attempts to incorporate financial, environmental, and social capital into a comprehensive framework that can help companies analyze their current processes, innovate, and identify new sources of revenue and cost reduction.

Table 5 Relevant manufacturing data related standards

\begin{tabular}{l|l}
\hline $\begin{array}{l}\text { Information } \\
\text { Model }\end{array}$ & Description \\
\hline AP203 & $\begin{array}{l}\text { Application Protocol for Configuration Controlled Design [37]. } \\
\text { AP203 defines the geometry, topology, and configuration management data of solid } \\
\text { models for mechanical parts and assemblies. AP-203 Edition } 2 \text { is a new version of the AP- } \\
203 \text { standard for exchanging 3D geometry between CAD systems. It includes Geometric } \\
\text { Dimensions \& Tolerances (GD\&T) data. The new data has been designed to meet the } \\
\text { requirements of design and manufacturing so the same model has also been incorporated } \\
\text { into AP-238. }\end{array}$ \\
\hline AP214 & $\begin{array}{l}\text { Core Data for Automotive Mechanical Design Processes [38]. } \\
\text { AP214, designed for the automotive industry, defines the core data for the automotive } \\
\text { mechanical design process, specifically the car body, power train, chassis, and the interior }\end{array}$ \\
\hline
\end{tabular}




\begin{tabular}{|c|c|}
\hline & $\begin{array}{l}\text { parts of a car. AP214 goes well beyond AP203, providing a far more comprehensive model } \\
\text { for automotive applications and covering the lifecycle of a design from engineering } \\
\text { through manufacturing. It also covers such design issues such as colors and layers, } \\
\text { geometric dimensioning and tolerancing, and design intent. }\end{array}$ \\
\hline AP219 & Application Protocol for Dimensional inspection information exchange [39]. \\
\hline AP223 & $\begin{array}{l}\text { Application protocol for casting [40]. } \\
\text { STEP AP } 223 \text { is part of a large standards effort to allow permanent storage and retrieval of } \\
\text { technical and process information for castings. }\end{array}$ \\
\hline AP224 & $\begin{array}{l}\text { Application Protocol for Mechanical Product Definition for Process Planning Using } \\
\text { Machining Features [41]. } \\
\text { AP224 is a vendor-independent digital product data specification that includes all } \\
\text { information needed to manufacture and assemble a machined part. In addition to part } \\
\text { geometry (dimension and tolerance) information, AP224 captures part features, material, } \\
\text { surface finish and other notational information needed in manufacturing. }\end{array}$ \\
\hline AP233 & $\begin{array}{l}\text { Application protocol for Systems Engineering and Design [42]. } \\
\text { AP233 is an information model designed as a neutral data exchange capability for data } \\
\text { created by Systems Engineering computer applications. }\end{array}$ \\
\hline $\begin{array}{l}\text { AP238 (ISO } \\
14649)\end{array}$ & $\begin{array}{l}\text { Application Protocol for Computerized Numerical Controllers [43]. } \\
\text { AP-238 is the official ISO STEP number for the STEP-NC standard. In AP-238 the } \\
\text { information required to control a machine is linked to the information created by CAD and } \\
\text { CAM systems to create a truly independent, fully documented CNC control file for the first } \\
\text { time. ISO } 14649 \text { is the machining data model underlying AP-238. The authors of ISO } \\
14649 \text { assessed the state of the art in CNC, and developed an object-oriented data model } \\
\text { based on the concepts of features and working steps that reflected today's high- } \\
\text { performance machining needs. AP-238 takes this data model and brings it into the suite of } \\
\text { STEP standards, so that CNCs can be fully integrated with CAD, CAM, CAPP and other } \\
\text { CA- applications. AP-238 defines a new interface for existing systems. }\end{array}$ \\
\hline AP240 & $\begin{array}{l}\text { Application Protocol For Process Plans For Machined Products [44, 45]. } \\
\text { STEP AP240 can support macro process planning by connecting CAPP with CAM. This is } \\
\text { because AP240 defines such a high-level process plan for a machined part, and contains } \\
\text { data about manufacture of a single piece or assembly of single piece parts. It serves as an } \\
\text { interface for capturing technical data out of the upstream application protocols, and issuing } \\
\text { work instructions for the tasks required to manufacture a part and the information required } \\
\text { to support NC programming of processes specified in the process plan. }\end{array}$ \\
\hline CMSD & $\begin{array}{l}\text { Data specification for efficient exchange of manufacturing life-cycle data in a simulation } \\
\text { environment [46]. The objective leads to: foster the development and use of simulations in } \\
\text { manufacturing operations, facilitate data exchange between simulation and other } \\
\text { manufacturing software applications, enable and facilitate better testing and evaluation of } \\
\text { manufacturing software, increase manufacturing application interoperability. }\end{array}$ \\
\hline ISO14040 & $\begin{array}{l}\text { ISO 14040:2006 [47] describes the principles and framework for life cycle assessment } \\
\text { (LCA) including: definition of the goal and scope of the LCA, the life cycle inventory } \\
\text { analysis (LCI) phase, the life cycle impact assessment (LCIA) phase, the life cycle } \\
\text { interpretation phase, reporting and critical review of the LCA, limitations of the LCA, the } \\
\text { relationship between the LCA phases, and conditions for use of value choices and optional } \\
\text { elements. }\end{array}$ \\
\hline ISO14064 & $\begin{array}{l}\text { ISO 14064-1:2006 [48] specifies principles and requirements at the organization level for } \\
\text { quantification and reporting of greenhouse gas (GHG) emissions and removals. It includes } \\
\text { requirements for the design, development, management, reporting and verification of an } \\
\text { organization's GHG inventory. }\end{array}$ \\
\hline ISO14065 & $\begin{array}{l}\text { ISO 14065:2007 [49] specifies principles and requirements for bodies that undertake } \\
\text { validation or verification of greenhouse gas (GHG) assertions. It is GHG programme } \\
\text { neutral. If a GHG programme is applicable, the requirements of that GHG programme are } \\
\text { additional to the requirements of ISO 14065:2007. }\end{array}$ \\
\hline ISO50001 & $\begin{array}{l}\text { The future ISO } 50001 \text { [50] will establish a framework for industrial plants, commercial } \\
\text { facilities or entire organizations to manage energy. Targeting broad applicability across }\end{array}$ \\
\hline
\end{tabular}




\begin{tabular}{l|l}
\hline & $\begin{array}{l}\text { national economic sectors, the standard could influence up to } 60 \% \text { of the world's energy } \\
\text { use. }\end{array}$ \\
\hline RS274D & $\begin{array}{l}\text { RS274D is the data standard currently used to tell CNC systems how to make a part [51]. } \\
\text { An RS274D file contains a list of instructions called G-codes. Each code tells the CNC } \\
\text { machine where to move the cutting tool next. If the CNC executes all of the instructions } \\
\text { correctly, then the part is made. Each code is very primitive and an RS27D file needs to } \\
\text { contain hundreds of thousands of codes to make a part. The CNC is not given any } \\
\text { information about what it is making or why the instructions have to be executed in the } \\
\text { given order. Therefore, no optimizations can be made on the control. The RS274D standard } \\
\text { is also limited in functionality, and CNC vendors have invariably extended it to include } \\
\text { newer features in their controls such as spline interpolation. These "dialects" are not } \\
\text { standardized, so programs written for one vendor's CNC are unlikely run on another } \\
\text { vendor's CNC. }\end{array}$ \\
\hline IGES & $\begin{array}{l}\text { IGES is a standard for transferring drawing information between CAD systems and } \\
\text { between customers and suppliers [52]. When a customer wants a job shop to make a part, it } \\
\text { sends a description of the part as a drawing in an IGES file. The job shop then reads that } \\
\text { IGES file into a Computer Aided Manufacturing (CAM) system and an operator uses it to } \\
\text { generate the RS274D code necessary to make the part on a specific machine tool. It can } \\
\text { take quite a long time for the operator to convert the drawing into RS274D codes and if } \\
\text { anything changes the whole process has to start again. The people who developed IGES } \\
\text { used the lessons learned to develop an international standard for the complete life cycle of } \\
\text { a product and called it STEP. There will be no more versions of IGES after the current one. }\end{array}$ \\
\hline
\end{tabular}

